\title{
ANALISIS KELAYAKAN USAHATANI PADI PETANI TRANSMIGRAN DI KAMPUNG MARGAMULYA DISTRIK SEMANGGA KABUPATEN MERAUKE PROPINSI PAPUA
}

\author{
Ineke Nursih Widyantari $^{1}$, Gerzon Jokomen Maulany ${ }^{2}$, Nila Wijayanti ${ }^{3}$ \\ ${ }^{1}$ Jurusan Agribisnis, Fakultas Pertanian, Universitas Musamus Merauke \\ Jl. Kamizaun, Mopah lama, Merauke Papua 99617 \\ ${ }^{2}$ Jurusan Sistem Informasi, Fakultas Teknik, Universitas Musamus Merauke \\ Jl. Kamizaun, Mopah lama, Merauke Papua 99617 \\ ${ }^{3}$ Jurusan Agribisnis, Fakultas Pertanian, Universitas Samawa \\ Jl. Bypass Sering, Kerato, Unter Iwes, Sumbawa 84316 \\ *Corresponding author: ineke_nw@unmus.ac.id
}

\begin{abstract}
Margamulya is one of the villages in the Merauke Regency, which is inhabited by many transmigrant farmers from the Javanese ethnic. They introduce rice farming to local residents in Merauke Regency. The purpose of this research is to figure out the received income, output cost, profitability, and feasibility of rice farming in Margamulya Village, Semangga District, Merauke Regency, Papua. The data used in this study are primary data and secondary data. Primary data was obtained from questionnaires and interviews, while the secondary data was obtained from Central Bureau Statistics of Merauke Regency. The results showed rice farming in Margamulya Village, Semangga District, Merauke Regency is feasible to develop with the received profit is IDR.9,864,480, the total cost is IDR.12,176,495, the profitability of 0.81 , and $R / C$ value of 1.81 .
\end{abstract}

Keywords: feasibility, finance, rice farming, transmigrant farmers

\begin{abstract}
Abstrak: Kampung Margamulya merupakan salah satu kampung yang terdapat di Distrik Semangga Kabupaten Merauke, yang banyak didiami petani transmigran berasal dari Suku Jawa. Para petani inilah yang memperkenalkan usahatani padi kepada penduduk lokal di Kabupaten Merauke. Tujuan dari penelitian ini adalah untuk mengetahui pendapatan yang diterima, biaya yang dikeluarkan, profitabilitas, dan kelayakan usahatani padi sawah di Kampung Margamulya Distrik Semangga Kabupaten Merauke, Papua. Data yang digunakan dalam penelitian ini adalah data primer dan data sekunder. Data primer diperoleh dari kuisioner dan wawancara, sedangkan data sekunder diperoleh dari BPS Kabupaten Merauke. Hasil dari penelitian ini menunjukkan bahwa usahatani padi sawah di Kampung Margamulya Distrik Semangga Kabupaten Merauke layak dikembangkan dengan keuntungan yang diterima sebesar Rp9.864.480, biaya total sebesar Rp12.176.495, profitabilitas sebesar 0,81 dan nilai $\mathrm{R} / \mathrm{C}$ sebesar 1,81 .
\end{abstract}

Kata kunci: kelayakan, usahatani, padi sawah, petani transmigran

\section{PENDAHULUAN}

Kabupaten Merauke merupakan kabupaten yang terdapat di Papua dan di era pemerintahan Presiden Joko Widodo dimaklumatkan menjadi lumbung pangan bagi wilayah timur Indonesia. Kabupaten Merauke memiliki tanah yang datar dengan luas tanam padi 44.347 .30 ha, luas panen padi 43.670 .30 ha, produksi padi $190.496,36$ ton dan produktivitas padi sebesar 4,36 ton/ha (Badan Pusat Statistik Kabupaten Merauke, 2017). Walaupun dimaklumatkan sebagai daerah lumbung pangan padi akan tetapi secara teknis 
performa usahatani padi di Kabupaten Merauke belum efisien baik performa petani lokal (Widyantari et al., 2018) maupun performa petani transmigran (Widyantari et al., 2019), dan sudah efisien untuk performa penggilingan padi (Widyantari et al., 2020).

Salah satu kampung yang terdapat di Kabupaten Merauke adalah Kampung Margamulya di Distrik Semangga. Petani transmigran yang berasal dari Suku Jawa banyak yang tinggal di Kampung Margamulya. Para petani transmigran inilah yang mengenalkan cara bercocok tanam padi pada penduduk lokal di Kabupaten Merauke. Kampung Margamulya termasuk salah satu kampung di Kabupaten Merauke yang memiliki tanaman pangan unggulan yaitu padi (Widyantari dan Maulany, 2020), karena berada dalam wilayah Distrik Semangga, dengan produksi padi sebesar 55.184,36 ton pada tahun 2019, luas panen sebesar 9614,00 ha, dan produktivitas padi sebesar 5,74 ton/ha (Badan Pusat Statistik Kabupaten Merauke, 2020). Lahan sawah di Kampung Margamulya merupakan lahan sawah non irigasi. Pengairan sawah dilakukan dengan menampung air hujan, sehingga dalam satu tahun petani hanya dapat menanam padi sebanyak dua kali musim tanam. Di samping itu juga infrastruktur pertanian yang masih terbatas dan produktivitas padi yang rendah.

Melihat uraian diatas maka perlu dilakukan penelitian bagaimana kelayakan usahatani padi di Kampung Margamulya Distrik Semangga Kabupaten Merauke. Penelitian mengenai kelayakan usahatani padi sebelumnya sudah dilakukan oleh Ningrum dan Effendy (2016) serta Ma'ruf et al. (2019) yang meneliti mengenai pendapatan dan kelayakan usahatani padi, sedangkan penelitian ini meneliti tingkat pendapatan, besar biaya usahatani, profitabilitas, dan kelayakan usahatani. Perbedaan lainnya adalah dalam penelitian ini usahatani padi sudah dilakukan dengan menggunakan mesin yaitu traktor untuk mengolah tanah dan combine harvester untuk memanen padi.

Adapun tujuan penelitian ini adalah untuk mengetahui besarnya pendapatan, biaya yang dikeluarkan, profitabilitas dan kelayakan usahatani padi sawah di Kampung Margamulya Distrik Semangga Kabupaten Merauke, Papua. Urgensi penelitian ini adalah agar diketahui kelayakan usahatani padi di Kabupaten Merauke, sehingga dapat membantu pihak yang berwenang dalam hal ini Dinas Tanaman Pangan, Holtikultura, dan Perkebunan Kabupaten Merauke untuk dapat mengambil kebijakan yang tepat dalam pengembangan usahatani padi guna mewujudkan Merauke sebagai lumbung pangan di Daerah Timur Indonesia.

\section{METODE PENELITIAN}

Penelitian ini menggunakan metode deskriptif analitif yang bertujuan untuk menggambarkan usahatani padi di Kampung Margamulya Distrik Tanah Miring Kabupaten Merauke. Penentuan lokasi penelitian dilakukan dengan menggunakan metode purposive atau sengaja, berdasarkan pertimbangan merupakan daerah sentra padi. Kampung Margamulya terletak di Distrik Semangga yang merupakan salah satu sentra padi di Kabupaten Merauke. Teknik pengambilan sampel menggunakan simple random sampling, dengan jumlah sampel 52 petani padi. Data yang digunakan adalah data primer yang diperoleh dari hasil observasi dan wawancara dengan menggunakan kuisioner, dan data sekunder didapat dari BPS Kabupaten Merauke. Analisis yang digunakan adalah analisis pendapatan usahatani, keuntungan usahatani, profitabilitas, dan kelayakan dengan rumus sebagai berikut:

Analisis pendapatan:

$$
\begin{aligned}
& P d=T R-T C \\
& T R=Y \cdot P y \\
& T C=F C+V C
\end{aligned}
$$

\section{Keterangan:}

$\mathrm{Pd}=$ pendapatan usahatani

$\mathrm{TR}=$ total penerimaan (total revenue)

$\mathrm{TC}=$ total biaya (total cost)

$\mathrm{FC}=$ biaya tetap (fixed cost)

$\mathrm{VC}=$ biaya variabel (variabel cost)

$\mathrm{Y}=$ produksi yang diperoleh dalam usahatani Py $=$ harga $Y$

Keuntungan usahatani menurut (Soekartawi, 2002) merupakan selisih antara pendapatan dan semua biaya dengan rumus seperti pada persamaan (4). 


$$
\pi=T R-T C
$$

Keterangan:

$$
\begin{array}{ll}
\pi & =\text { keuntungan } \\
\text { TR } & =\text { total penerimaan } \\
\text { TC } & =\text { total biaya }
\end{array}
$$

Profitabilitas yaitu kemampuan untuk menghasilkan laba, yang secara matematis dapat dirumuskan (Debertin, 2012) sebagai berikut:

$$
P_{\text {rof }} \text { ttabttitas }=\frac{\pi}{T C} \times 100 \%
$$

Keterangan:

$$
\pi \quad=\text { keuntungan }
$$$$
\mathrm{TC}=\text { biaya total }
$$

Dengan kriteria profitabilitas $>0$ berarti usahatani padi di Kampung Margamulya Distrik Semangga Kabupaten Merauke menguntungkan. Profitabilitas $=0$ berarti usahatani padi di Kampung Margamulya Distrik Semangga Kabupaten Merauke mengalami BEP (impas). Profitabilitas $<0$ berarti usahatani padi di Kampung Margamulya Distrik Semangga Kabupaten Merauke yang diusahakan tidak menguntungkan (Episar et al., 2018)

Analisis R/C Ratio:

B/Cratio $=\frac{T R}{T C}$

Keterangan:

$$
\begin{aligned}
& \mathrm{R} / \mathrm{C} \text { ratio }=\text { Return Cost Ratio } \\
& \mathrm{TR}=\text { total penerimaan (revenue) } \\
& \mathrm{TC}=\text { biaya (cost) }
\end{aligned}
$$

Dengan kriteria $\mathrm{R} / \mathrm{C}>1$, usahatani padi di Kampung Margamulya Distrik Semangga Kabupaten Merauke menguntungkan/layak (tambahan manfaat/penerimaan lebih besar dari tambahan biaya). $\mathrm{R} / \mathrm{C}<1$, usahatani padi di Kampung Margamulya Distrik Semangga Kabupaten Merauke rugi/tidak layak (tambahan biaya lebih besar dari tambahan penerimaan). $\mathrm{R} / \mathrm{C}=1$, usahatani padi di Kampung Margamulya Distrik Semangga Kabupaten Merauke impas atau tidak untung tidak rugi (tambahan penerimaan sama dengan tambahan biaya) (Soekartawi, 2002).

\section{HASIL DAN PEMBAHASAN}

\section{Karakteristik Petani Responden}

\begin{tabular}{|c|c|c|c|}
\hline No & Keterangan & Jumlah & $\begin{array}{l}\text { Persen } \\
\text { tase (\%) }\end{array}$ \\
\hline \multirow[t]{3}{*}{1.} & Jenis Kelamin & & \\
\hline & Wanita & 8 & $15 \%$ \\
\hline & Pria & 44 & $85 \%$ \\
\hline \multirow[t]{7}{*}{2.} & Umur (tahun) & & \\
\hline & $20-29$ & 3 & $6 \%$ \\
\hline & $30-39$ & 7 & $13 \%$ \\
\hline & $40-49$ & 15 & $29 \%$ \\
\hline & $50-59$ & 9 & $17 \%$ \\
\hline & $60-69$ & 14 & $27 \%$ \\
\hline & $\geq 70$ & 4 & $8 \%$ \\
\hline \multirow[t]{8}{*}{3.} & Pendidikan (tahun) & & \\
\hline & Tidak Sekolah & 1 & $2 \%$ \\
\hline & Tidak Tamat Sd & 5 & $10 \%$ \\
\hline & Tamat SD & 28 & $54 \%$ \\
\hline & SMP & 10 & $19 \%$ \\
\hline & SMA & 6 & $12 \%$ \\
\hline & D3 & 1 & $2 \%$ \\
\hline & S1 & 1 & $2 \%$ \\
\hline \multirow[t]{6}{*}{4.} & $\begin{array}{l}\text { Pengalaman Bertani } \\
\text { (tahun) }\end{array}$ & & \\
\hline & $\leq 9$ & 4 & $8 \%$ \\
\hline & $10-19$ & 11 & $21 \%$ \\
\hline & $20-29$ & 16 & $31 \%$ \\
\hline & $30-39$ & 17 & $33 \%$ \\
\hline & $\geq 40$ & 4 & $8 \%$ \\
\hline \multirow[t]{5}{*}{5.} & $\begin{array}{l}\text { Jumlah Tanggungan } \\
\text { (jiwa) }\end{array}$ & & \\
\hline & 2 & 9 & $17 \%$ \\
\hline & 3 & 15 & $29 \%$ \\
\hline & 4 & 21 & $40 \%$ \\
\hline & $\geq 5$ & 7 & $13 \%$ \\
\hline
\end{tabular}

Responden dalam penelitian ini adalah petani padi di Kampung Margamulya, Distrik Semangga, Kabupaten Merauke, Papua. Karakteristik petani padi sawah di Kampung Margamulya dapat dilihat pada Tabel 1.

Tabel 1. Karakteristik petani di Kampung Margamulya, Distrik Semangga Kabupaten Merauke, Papua

Sumber: Data Primer, 2021

Tabel 1 menunjukkan bahwa responden yang dominan dalam penelitian ini adalah berjenis kelamin pria dan didominasi umur 40- 
49 tahun. Pada tingkat ini umur petani masih termasuk dalam kategori umur produktif (Onibala et al., 2017). Menurut Palobo (2019) petani yang berada pada kisaran umur produktif dapat menerima dan mengadopsi inovasi teknologi. Sedangkan menurut Thamrin et al. (2012) tingkat umur petani yang masih produktif akan membuat usahatani yang dijalankan petani sesuai dengan pola pemikiran yang baik sehingga akan berpengaruh pada kelangsungan usahatani yang dijalankan

Tingkat pendidikan petani di Kampung Margamulya Distrik Semangga masih tergolong rendah karena didominasi tingkat pendidikan pada jenjang SD sebanyak 54\%. Hal ini sesuai dengan penelitian Hidayani et al. (2019) dimana jumlah petani yang berpendidikan rendah lebih dominan yaitu sebanyak $66 \%$. Tingkat pendidikan ini menjadi faktor penentu dalam pengembangan suatu usaha, karna petani yang memiliki pendidikan tinggi maka akan semakin maju dalam pola pikirnya (Ali et al., 2015), petani yang memiliki pendidikan tinggi akan lebih cepat dalam mengadopsi inovasi, dibandingkan petani yang berpendidikan rendah (Kurniati, 2015), dan pendidikan petani berpengaruh dalam meningkatkan produktivitas pertanian, petani yang pendidikannya tinggi akan lebih mudah dalam mengadopsi teknologi modern (Paltasingh dan Goyari, 2018).

Pengalaman bertani petani padi di Kampung Margamulya Distrik Semangga paling dominan adalah antara 30-39 tahun yakni sebanyak $33 \%$ petani. Ini menunjukkan bahwa pengalaman bertani padi di Kampung Margamulya sudah lama. Semakin lama pengalaman petani dalam berusahatani maka akan berpengaruh pada kebiasaan, kemahiran, dan keterampilan atau keahlian petani dalam melakukan kegiatan usahatani (Mulyati, 2014), efisiensi usahatani menjadi meningkat (Orewa dan Izekor, 2012), keahlian petani menjadi terspesialisasi (Michael, 2011). Semakin lama pengalaman petani maka semakin dalam pengetahuan tentang berusahatani. Sedangkan menurut Sundari (2011) Pengalaman yang cukup lama akan berpengaruh pada sikap petani dalam mengambil keputusan yang berkaitan dengan inovasi baru, karena untuk bisa menerapkan inovasi baru maka dibutuhkan keberanian untuk menanggung resiko.
Jumlah tanggungan petani padi sawah di Kampung Margamulya yang paling dominan adalah empat jiwa, ini berarti jumlah tanggungan petani masuk dalam kategori cukup banyak. Jumlah tanggungan petani ini berdampak pada tingkat kesejahteraan petani, karena menurut Robiyan et al. (2014) Semakin banyak jumlah tanggungannya maka semakin banyak kebutuhan yang harus dikeluarkan petani. Apabila semakin banyak kebutuhan yang harus dipenuhi ini berarti petani harus dapat meningkatkan pendapatannya.

\section{Usahatani Padi}

Petani padi sawah di Kampung Margamulya dalam satu tahunnya melakukan penanaman padi sebanyak dua kali. Hal ini dikarenakan keterbatasan air di Kampung Margamulya, sehingga hanya mampu bercocok tanam sebanyak dua kali setiap tahunnya. Keterbatasan air ini dikarenakan pertanian di Kampung Margamulya pada khususnya dan Kabupaten Merauke pada umumnya hanya mengandalkan air hujan. Sehingga apabila persediaan air tinggal sedikit atau bahkan kering, maka petani tidak dapat menanam padi.

Tabel 2 menunjukkan bahwa jenis pupuk yang digunakan petani padi di Kampung Margamulya Distrik Semangga Kabupaten Merauke ada tiga macam yaitu pupuk urea, pupuk SP 36, dan pupuk ponska. Benih padi yang digunakan petani rata-rata berasal dari hasil panen musim tanam sebelumnya. Penggunaan tenaga kerja manusia hanya digunakan saat melakukan pemupukan, penanaman, penyemprotan pestisida, dan perawatan tanaman. Sehingga untuk satu hektar lahan dibutuhkan tenaga kerja $23 \mathrm{HOK} / \mathrm{ha}$. Sistem tanam padi yang dilakukan petani di Kampung Margamulya ada dua sistem tanam yaitu sistem tanam pindah dimana pembibitan padi dengan persemaian, dan sistem tanam benih langsung yaitu sistem tanam dengan cara disebar tanpa persemaian. Pengolahan tanah sawah dilakukan dengan menggunakan mesin traktor, sedangkan pemanenan padi dilakukan dengan menggunakan mesin combain harvester, dimana setiap satu hektar sawah hanya membutuhkan waktu memanen kurang lebih empat jam/ha. 
Tabel 2. Deskripsi input produksi dan manajemen usahatani Kampung Margamulya, Distrik Semangga Kabupaten Merauke

\begin{tabular}{llr}
\hline No & Uraian & $\begin{array}{c}\text { Penggunaan } \\
\text { Teknis }\end{array}$ \\
\hline 1 & Lahan (ha) & 1 \\
2 & Pupuk Urea (kg/ha) & 92 \\
3 & Pupuk SP 36 (kg/ha) & 96 \\
4 & Pupuk Ponska (kg/ha) & 119 \\
5 & Benih (kg/ha) & 43 \\
6 & Pestisida (liter/ha) & 1.14 \\
7 & Tenaga Kerja (HOK/ha) & 23 \\
8 & Traktor (jam/ha) & 8 \\
9 & Combine harvester (jam/ha) & 4 \\
\hline
\end{tabular}

Sumber: Olah Data Primer, 2021

\section{Penerimaan Usahatani Padi Sawah}

Jumlah penerimaan yang diterima petani padi nilainya tergantung dari jumlah produksi beras yang dihasilkan dan harga jual beras. Semakin banyak beras yang dihasilkan maka akan semakin banyak beras yang dijual, semakin tinggi harga jual beras maka pendapatan yang diterima petani juga akan semakin besar. Adapun rata-rata pendapatan yang diterima dan biaya yang dikeluarkan petani padi Kampung Margamulya dapat dilihat pada Tabel 3.

Hasil dari perhitungan profitabilitas menunjukkan bahwa usahatani padi sawah di Kampung Margamulya, Distrik Semangga Kabupaten Merauke, Papua menguntungkan, hal ini dikarenakan nilai profitabilitas yang diperoleh adalah sebesar 0,81 atau $0.81>0$. Semakin tinggi nilai profitabilitasnya maka semakin besar keuntungan yang di peroleh. Hal ini sesuai dengan hasil penelitian pada peternak ayam kampung di Distrik Semangga Kabupaten Merauke dengan profitabilitas 0,62 dengan keuntungan Rp2.304.488 (Widyantari, 2015). Jadi profitabilitas yang diperoleh petani padi di Kampung Margamulya lebih besar yaitu 0.81 dengan pendapatan/keuntungan sebesar Rp9.864.480.

Tabel 3 menunjukkan bahwa rata-rata pendapatan yang diterima petani di Kampung Margamulya Distrik Semangga adalah Rp9.864.480.

Analisis Profitabilitas

Profitabilitas $=(\pi / \mathrm{TC}) \times 100 \%$

$$
\begin{aligned}
& =(9.864 .480 / 12.176 .495) \times 100 \% \\
& =0,81
\end{aligned}
$$

Tabel 3. Analisis pendapatan petani satu musim tanam padi sawah di Kampung Margamulya, Distrik Semangga,

\begin{tabular}{|c|c|c|}
\hline No & Uraian & Nilai Rp/1 ha \\
\hline 1 & Rata-rata penerimaan & 22.040 .975 \\
\hline \multirow[t]{5}{*}{2} & Rata-rata biaya : & \\
\hline & \multicolumn{2}{|l|}{ Rata-rata biaya tetap: } \\
\hline & Biaya sewa lahan & 2.051 .282 \\
\hline & $\begin{array}{ll}\text { Biaya penyusutan } \\
\text { peralatan }\end{array}$ & 294.548 \\
\hline & Total biaya tetap: & 2.345 .830 \\
\hline & Rata-rata biaya variabel & \\
\hline & Biaya pupuk urea & 169.712 \\
\hline & Biaya pupuk SP 36 & 197.788 \\
\hline & Biaya pupuk ponska & 257.548 \\
\hline & Biaya benih & 291.750 \\
\hline & Biaya pestisida & 241.849 \\
\hline & Biaya tenaga kerja & 2.317 .869 \\
\hline & Biaya sewa traktor & 1.213 .462 \\
\hline & Biaya sewa combain & 1.513 .462 \\
\hline & Biaya karung & 307.606 \\
\hline & Biaya angkut & 391.747 \\
\hline & Biaya penjemuran & 782.885 \\
\hline & Biaya penggilingan & 2.204 .098 \\
\hline & Total biaya variabel & 9.889 .774 \\
\hline 3 & Total biaya $(\mathrm{A}+\mathrm{B})$ & 12.176 .495 \\
\hline 4 & $\begin{array}{l}\text { Pendapatan (penerimaan- } \\
\text { total biaya) }\end{array}$ & 9.864 .480 \\
\hline
\end{tabular}
Kabupaten Merauke, Papua.

Sumber: Olah Data Primer, 2021

\section{Analisis R/C Ratio}

Analisis ini digunakan untuk menguji seberapa jauh nilai rupiah yang digunakan dalam usahatani sehingga memberikan sejumlah nilai penerimaan sebagai manfaat. Nilai $\mathrm{R} / \mathrm{C}$ yang semakin tinggi maka semakin besar pula penerimaan dalam rupiah yang diperoleh dari setiap rupiah yang dikeluarkan dan semakin bagus kedudukannya dalam usahatani (Mulyo et al., 2017). Kelayakan usahatani padi sawah di Kampung Marga Mulya Distrik Semangga Kabupaten Merauke menggunakan analisis R/C Ratio (Revenue and Cost Ratio).

$$
\begin{aligned}
\mathrm{R} / \mathrm{C} & =\mathrm{TR} / \mathrm{TC} \\
& =\mathrm{Rp} 22.040 .975 / \mathrm{Rp} 12.176 .495 \\
& =1,81
\end{aligned}
$$

Hasil perhitungan $\mathrm{R} / \mathrm{C}$ memiliki angka lebih besar dari satu atau 1,81>1 ini berarti usahatani padi di Kampung Margamulya Distrik Semangga Kabupaten Merauke 
menguntungkan sehingga layak untuk dijalankan. Nilai R/C sebesar 1,81 ini berarti bahwa setiap Rp100 biaya yang dikeluarkan maka akan diperoleh pendapatan sebesar Rp181.

\section{KESIMPULAN DAN SARAN}

Usahatani padi sawah di Kampung Margamulya Distrik Semangga Kabupaten Merauke Papua dapat disimpulkan bahwa pendapatan rata-rata yang diperoleh petani untuk satu kali tanam adalah sebesar Rp9.864.480. Total biaya usahatani rata-rata untuk sekali tanam adalah Rp12.176.495, dengan profitabilitas usahatani padi sebesar 0,81 , sehingga nilai $\mathrm{R} / \mathrm{C}$ yang diperoleh sebesar 1,81. Dengan demikian berarti usahatani padi di Kampung Margamulya Distrik Semangga Kabupaten Merauke menguntungkan dan layak untuk diusahakan.

Petani padi di Kampung Margamulya dalam satu tahun hanya dapat menanam padi sebanyak dua kali tanam, hal ini dikarenakan keterbatasan tersedianya air, sehingga perlu segera direalisasikan pembangunan waduk supaya petani di Kampung Margamulya dan juga kampung-kampung lain di Kabupaten Merauke dapat menanam padi lebih dari dua kali tanam dalam setahun.

\section{DAFTAR PUSTAKA}

Ali, J., Delis, A., \& Hodijah, S. (2015). Analisis produksi dan pendapatan petani karet di Kabupaten Bungo. Perspektif Pembiayaan Dan Pembangunan Daerah, 2(4), 201-208.

Badan Pusat Statistik Kabupaten Merauke. (2017). Merauke Dalam Angka. Merauke: BPS Merauke. Retrieved from https://meraukekab.bps.go.id/website/pdf publikasi/Kabupaten-Merauke-DalamAngka-2017.pdf

Badan Pusat Statistik Kabupaten Merauke. (2020). Kabupaten Merauke Dalam Angka. Merauke: BPS Merauke. Retrieved from https://meraukekab. bps.go.id/publication/download.html?
Debertin, D. L. (2012). Agricultural Production Economics (Second Edi). Kentucky: Departement of Agricultural Economics, University of Kentucky.

Episar, E., Widuri, S., \& Afrianto, E. (2018). Analisis usaha dan profitabilitas pada usaha budidaya ikan lele studi kasus Kelompok Pembudidaya Ikan (Pokdakan) Ngaol Jaya Desa Sungai Ulak Kecamatan Nalo Tantan Kabupaten Merangin. Jurnal Agri Sains, 2(2), 1-9.

Hidayani, S., Darwanto, D. H., Irham, \& Jamhari. (2019). Factors influencing farmers to join Warehouse Receipt System in Barito Kuala Regency, South Kalimantan, Indonesia. EurAsian Journal of BioSciences, 13(2), 21772183.

Kurniati, D. (2015). Perilaku petani terhadap risiko usahatani kedelai di Kecamatan Jawai Selatan Kabupaten Sambas. Jurnal Social Economic of Agriculture, 4(1), $32-36$.

Ma'ruf, M. I., Kamaruddin, C. A., \& Muharief, A. (2019). Analisis pendapatan dan kelayakan usahatani padi di Kecamatan Pitu Riawa Kabupaten Sidrap. Jurnal Sosial Ekonomi Pertanian, 15(3), 193204. https://doi.org/10.20956/jsep.v15i3. 7021.

Michael, O. F. (2011). Mesuaring technical efficiency of Yam Farmers- a stochastic parametric approach. Agricultural Journal, 6(2), 40-46.

Mulyati, H. (2014). Analisis produksi dan pendapatan usahatani padi sawah di Desa Jono Oge Kecamatan Sigi Biromaru Kabupaten Sigi. Agrotekbis, 2(1), 54-61.

Mulyo, J. H., Irham, Jumeri, Perwitasari, H., Rohmah, F., \& Rosyid, A. H. A. (2017). Studi kelayakan komoditas usahatani daerah perbatasan pulau sebatik kalimantan utara. Prosiding Seminar Nasional Dan Call For Ppaers, VII 17-18(November), 688-694. 
Ningrum, N. W. \& Effendy, E. (2016). Analisis pendapatan dan kelayakan usahatani padi sawah di Desa Laantula Jaya Kecamatan Witaponda Kabupaten Morowali. Agrotekbis, 4(3), 350-355.

Onibala, A. G., Sondakh, M. L., Kaunang, R., \& Mandei, J. (2017). Analisis faktorfaktor yang memengaruhi produksi padi sawah Di Kelurahan Koya, Kecamatan Tondano Selatan. Agri-Sosioekonomi, 13(2A), 237-242. https://doi.org/10.3579 1/agrsosek.13.2a.2017.17015.

Orewa, S. I., \& Izekor, O. B. (2012). Technical efficiency analysis of Yam Production in Edo State: A Stochastic frontier approach. International Journal of Development and Sustainability, 1(2), 516-526.

Palobo, F. (2019). Analisis kelayakan usahatani jagung hibrida pada lahan kering Di Merauke, Papua. SEPA: Jurnal Sosial Ekonomi Pertanian Dan Agribisnis, 16(1), 1. https://doi.org/10.20961/sepa. v16i1.30112.

Paltasingh, K. R., \& Goyari, P. (2018). Impact of farmer education on farm productivity under varying technologies: Case of paddy growers in India. Agricultural and Food Economics, 6(1), 1-19. https:// doi.org/10.1186/s40100-018-0101-9.

Robiyan, R., Hasanuddin, T., \& Yanfika, H. (2014). Persepsi petani terhadap Program SL-PHT dalam meningkatkan produktivitas dan pendapatan usahatani kakao (Studi kasus petani kakao di Desa Sukoharjo 1 Kecamatan Sukoharjo Kabupaten Pringsewu). Jurnal Ilmu-Ilmu Pertanian, 2(3), 301-308.

Soekartawi, A. S. (2002). Analisis Usahatani. Jakarta: UI Press.
Sundari, M. T. (2011). Analisis biaya dan pendapatan usaha tani wortel di Kabupaten Karanganyar. SEPA: Jurnal Sosial Ekonomi Pertanian Dan Agribisnis 7(2), 119-126.

Thamrin, M., Herman, S., \& Hanafi, F. (2012). Pengaruh faktor sosial ekonomi terhadap pendapatan petani pinang. Agrium, 17(2), 85-94.

Widyantari, I. N. (2015). Analisis kelayakan finansial usaha ayam kampung Di Distrik Semangga Kabupaten Merauke. Agricola, 5(1), 47-54.

Widyantari, I. N., Jamhari, Waluyati, L. R., \& Mulyo, J. H. (2018). Does the tribe affect technical efficiency? Case study of local farmer rice farming in Merauke regency, Papua, Indonesia. International Journal of Mechanical Engineering and Technology, 9(11), 37-47.

Widyantari, I. N., Jamhari, Waluyati, L. R., \& Mulyo, J. H. (2019). Case study of farming from transmigrants and local farmers in the District of Semangga and Tanah Miring, Merauke Regency, Papua. International Journal of Civil Engineering And Technology (IJCIET), 10(02), 761-772.

Widyantari, I. N., Jamhari, Waluyati, L. R., \& Mulyo, J. H. (2020). Data Envelopment Analysis for measurement the performance of rice millings in Merauke Regency, Papua, Indonesia. EurAsian Journal of BioSciences, 14(2), 62616265.

Widyantari, I. N., \& Maulany, G. J. (2020). The Location Quotient approach for determination of superior food crop commodity in Merauke Regency, Province of Papua, Indonesia. EurAsian Journal of BioSciences, 14(2), 71117117. 